\title{
All My Buddies Was Male: Relationship Issues of Women With Addictions
}

\author{
Dorothy Henderson, $R N, P h D$, Carol Boyd, $R N, P h D$
}

\begin{abstract}
There is a common perception that women who abuse drugs and alcohol do not like women. How does this attitude relate to women's abuse of drugs, and what difference might it make to the nursing care of addicted women? The importance of relationships to self and others has been emphasized in nursing theories, recent theories of women's psychologic development, and the social models used to explain substance abuse. This article examines what is known about the interpersonal relationships of women with addictions, including those with men and with other women, and explores how those relationships are associated with women's substance abuse behaviors. A brief explanation of current theories of women's psychologic development is followed by a review of the literature regarding the relationships of women with addiction problems, highlighting their attitudes toward themselves as women and the importance of the adult mother-daughter relationship. Implications for the treatment of addicted women by nurses are discussed. JOGNN, 26, 469-476, 1997.
\end{abstract}

I've never been one for women. All my buddies was male and the women friends that I did have they weren't friends, really. I knew either they wanted somethin' out of me or I wanted somethin' out of them. Because I've never trusted women. I always said somehow they would backstab you. My sister always did me in and ended up backstabbin' me. My mother was never there, so how could I expect any other women to be right.-Belinda

The opening quote from "Belinda," a 23year-old resident in an all-women's treatment program, reflects several common perceptions about the nature of the interpersonal relationships of ad- dicted women: women who abuse drugs and alcohol do not like women; they will talk and behave as though they prefer the company of men; and they often have problematic relationships with their mothers and other female family members, which may be contributing factors in their dislike of women. Attempts to explain these have focused on the nature of addicted women's relationships with men and, to a lesser extent, on the nature of their relationships with other women. The inevitable question that stems from the claim by a woman that she does not like women becomes "what does it mean to be a woman and say that you do not like women?"

Attending to the importance of interpersonal relationships in the lives of addicted women is consistent with nursing theories, recent theories of women's psychologic development, and the social models used to explain substance abuse. Each of these emphasizes the importance of the environmental impact on individual behavior. In broad strokes, nursing theorists articulate the interconnection of the person and her health with her environment. On a more specific level, psychologic theories of women's development point to the salience of interpersonal relationships in women's lives and the need to understand adult women's relationships with other women, including their mothers (Chodorow, 1989; Collins, 1990; Greene, 1990; Miller, 1991). In addition, the social models of substance abuse propose that environment and the people within it are key factors in whether a person begins to engage in illicit drug use. Indeed, drug initiation often is thought to originate from the interplay of family, peers, and neighborhood, whereas drug abuse involves the interaction of friends, lovers, and paradoxically social isolation. Based on these theories, any attempt to explain 
women's behaviors of addiction must address the nature of their interpersonal relationships.

The purpose of this article is to examine what is known about the interpersonal relationships of women with addictions, including those with men and other women, and to explore possible explanations for the nature of these relationships and how they may contribute to women's substance abuse behaviors. We offer this information with the expectation that increasing our nursing knowledge of the interpersonal environment of women substance abusers will increase our ability to provide them with comprehensive and compassionate treatment. Providing compassionate care to addicted women, particularly addicted pregnant women, can be a challenge to nurses. We believe that a deeper understanding of addicted women's relationships with other women (including women who are nurses) is key to meeting that challenge.

In addition to addressing the interpersonal, we address the intrapersonal environment of the addicted woman (i.e., her attitude toward herself as a woman). As nurses, we long have recognized the importance of self-esteem to the well-being of the individual. We suggest in this article that a woman's attitude toward herself as a woman is a crucial component of her self-esteem, and in women with addiction, this attitude becomes a critical focus of treatment.

This article begins with a brief explanation of current theories of women's psychologic development. This is followed by a review of the literature regarding the relationships of women with addictions with themselves as women, with men, and with other women. In the latter, the mother-daughter relationship will be highlighted. The article concludes with a discussion of the implications of this knowledge for the treatment of addicted women by nurses.

\section{Psychologic Theories of Women's Development}

Most prevailing theories of addiction and most psychologic theories are rooted in the male experience; women, including women with addiction, often are understood in terms of "what is missing or different" from men. Increasingly, this bias is being addressed by theorists who focus their writings on women. The centrality of relationships in women's lives has been emphasized by a number of theories of women's development. More specifically, models have been developed that explore the nature of the mother-daughter relationship, articulating its impact on a woman's psychologic development, the ways it differs from male parental relationships and development, how these differences influence the nature of women's adult relationships, and the variations that ex- ist among cultural groups (Chodorow, 1989; Collins, 1990; Miller, 1991).

\section{Nost prevailing theories of addiction are rooted in the male experience; women with addictions often are understood in terms of "what is missing or different" from men with addictions.}

Women are the primary caregivers of both male and female children, which provides different developmental experiences for boys and girls (Chodorow, 1989). Whereas boys are required to separate from their primary caregiver to develop a male gender identity, girls are able to develop their female gender identity without that separation. This allows girls to develop a sense of self that is continuous and relational with others and to maintain flexible ego boundaries, resulting in different constructions of self for men and women. Whereas men in general value individuation and autonomy, women often strive for interdependence and connection. Thus, women are socialized to be concerned with the care and maintenance of their interpersonal relationships. This is both a strength (because it enables greater intimacy) and a problem (because it threatens autonomy for women's psychologic development).

"Self in relation" theory applies these ideas to the life situations of the adult woman (Miller, 1991). Within this theory, women with addictions would be expected to be more likely to maintain and nurture interpersonal relationships than would their male counterparts. Thus, we could anticipate that relationships would play a key role in women's substance abuse and recovery potential.

Similarly, Collins (1990) writes that self-definition for African-American women occurs within the context of their close, extended family relationships. She notes that the mother-daughter relationship of African-American women forms a significant social support network; that network might be less supportive when the mother is a substance abuser. Other writers have urged that for women of varying racial and ethnic identities, issues of psychologic development and interpersonal relationships must be considered within the context of racial oppression and cultural differences (Comaz-Diaz \& Greene, 1995). This caution may be even more salient when considering the societal context for women with addictions, in which the stereotypical media representation often is a woman of color. 


\section{The Addicted Woman's Relationships with Self as Woman, Men, and Other Women}

Attempts to understand the intra- and interpersonal relationships of women with addictions have fallen into three basic categories. The first, begun in the mid1970s, involved research and clinical practice that was based on a psychoanalytical model. Within this model, the negative attitudes of women with addictions toward women was framed as a psychologic problem of the individual woman related to a rejection of her female gender identity. The second category, which began a little later (the late 1970s), focused on the relationship of women with addictions to the men in their lives. The third model, of which little has been written, looked at women's relationships with other women and recently has included the adult mother-daughter relationship. In the following section, we discuss what is known about these three categories, reviewing the literature concerning the relationships of women with addictions with themselves as women, with men, and with other women.

\section{Relationship with Self as Woman}

Because I'm also a woman. I think I kind of forgot that part. I always knew I was female but I never did look at myself as the same as another woman. So they was like aliens to me.-Belinda

The attitude of substance-abusing women toward other women (and themselves as women) became a focus of research in the early 1970 s and has continued nationally and internationally into the 1990s (Douglas \& Nutter, 1986; Lara-Cantu, Medina-Mora, \& Gutierrez, 1990; Scida \& Vannicelli, 1979; Wilsnack, 1976). Inspired in part by clinical descriptions of women substance abusers who exhibited a preference for masculine company and behaviors (and perhaps by the social perception that any use of drugs and alcohol was a masculine behavior), these studies looked at the relationship between women's drug and alcohol abuse and their identity as female/feminine. Women alcoholics and drug abusers were believed to have a dissonance between their actual and desired sexual images or gender identities; this dissonance was characterized by an inner longing for greater femininity and an outer attraction to more masculine behaviors and roles. In an early analysis of sex role issues, drinking, and ethnicity, Wilsnack and Wilsnack (1978) reported that desire for traditional femininity among adolescent girls was strongest in whites, then Hispanics, African-Americans, and Native Americans.

Sex role research with this population has been criticized on a number of levels, including its questionable foundations and contradictory findings (Henderson \& Boyd, 1992; Lundy, 1987). The research was based on culturally defined and changing ideas of what constitutes feminine identity and contained inconsistent, con- tradictory, and at times interchangeable definitions of key concepts such as gender identity, sex role identity, and sexual identity. A more basic critique of this research lies in its androcentric foundation, in which women's problems are framed as sexual, whereas men's problems are considered generic (human). Most of the research on sex role conflict has been done with women substance abusers, implying that women's problems stem from their internal conflicts with their femininity. In contrast, much of the psychologic research done with male substance abusers has located men's problems in their conflicts with the external demands of society (see Henderson $\&$ Boyd, 1992, for a more in-depth discussion of this). Rather than looking at events in women's lives or the context of their lives, psychologic analyses looked at women only intrapersonally and described as pathologic their lack of embrace of the feminine role.

Despite the problems with sex role conflict research, this body of work has been helpful in identifying the problem of the critical attitude women substance abusers have toward women. Whereas the intrapersonal focus was too narrow and lacked a holistic perspective, its emphasis on the potential impact of women's negative attitudes toward other women on their own self-concept (as in, "what does it mean to you if you are a woman and you do not like women?") remains an important question.

\section{Relationships With Men}

Regardless of the drug (heroin, smokable cocaine [crack], or alcohol) female substance abusers are more likely than male ones to have been initiated to the drug by a member of the opposite sex (Henderson \& Boyd, 1995; Henderson, Boyd, \& Mieczkowski, 1994; Murphy \& Rosenbaum, 1992). Indeed, the drug use often is associated with an intimate relationship. In two studies of women who use crack, most of the women were initiated to crack by men who were either family members or boyfriends/lovers (Boyd \& Mieczkowski, 1990; Henderson et al., 1994). The same was not true for men who use crack. Similar patterns were found with women who use heroin (Rosenbaum, 1981). In addition, prostitution is a prevalent means of support for women's drug habits and seems to have increased with the introduction of crack (Bouknight, 1990). Degradation and manipulation characterize the exchange of sex for crack as women (and some men) provide sexual favors for the crack or money to buy crack (Ratner, 1993). In assessing the influence of male relationships on the drug use of women addicts, it is important to distinguish those relationships that are solely for purpose of acquiring drugs and those that may be more nurturing and healthy.

In addition to introducing women to drugs, men in relationships with women with addictions may impede women's treatment seeking. Women users of illicit drugs 
have reported feeling pressured by a spouse or lover to use drugs (Sowder, 1981) and encountering more opposition to entering treatment than do their male counterparts (Beckman \& Amaro, 1986). In addition, male partners of substance abusing women also are less likely to give support when the women are in treatment (Higgins, Budney, \& Bickel, 1994).

Male violence against women has been associated directly and indirectly with women's drug abuse. Recently, a number of studies have identified childhood sexual abuse as an antecedent to women's drug abuse (Boyd, 1993; Boyd, Blow, \& Orgain, 1993; Paone \& Chavkin, 1992). These studies have been conducted with African-American and white women, with women who abuse alcohol, and with women who abuse other drugs. Estimates of a history of sexual abuse for women in substance abuse treatment range from $30 \%$ to $75 \%$, leading many to suggest sexual trauma as a key contributor to women's drug abuse (Benward \& Densen-Gerber, 1971; Ladwig \& Anderson, 1989; Root, 1989). In addition to associations with childhood sexual abuse, women's drinking problems in adulthood have been linked to their having been raped (with the substance abuse occurring after the experience of rape), to being beaten in relationships with men, to experiencing more severe beatings in relationships, and to the experience of greater physical aggression in dating (Miller \& Testa, 1993).

\section{Relationships With Women}

And now, I'm not go'n' say I put all my trust in 'em. But I'm go'n' give 'em a chance. Bein' here, I learned to accept a woman as a woman. I learned that all women ain't bad. I might not be able to live with 'em, but I can if I want to. I don't have to knock women just for bein' a woman.-Belinda

Although addicted women appear to have the most problematic relationships with the men in their lives, they often have difficult relationships with women. Despite that recommendations for all-women treatment programs are increasing, we know little about the relationships of addicted women to other women in their lives.

\section{1 hereas opposite-sex relationships tend to revolve around the procurement and use of drugs, same-sex relationships seem to flounder on those same activities.}

Whereas opposite-sex relationships tend to revolve around the procurement and use of drugs, same-sex re- lationships seem to flounder on those same activities. The lifestyle of women who are addicted to drugs does not appear to encourage the establishment or maintenance of close relationships. In a study of women who use heroin, Tucker (1981) found that although women did have same-sex best friends, they were significantly more likely to report having "no friends" in their neighborhood and to describe themselves as more lonely than were women without addictions or men with addictions. Similar findings were reported in a comparison of alcoholic women and nonalcoholic women (Schilit \& Gomberg, 1987). Boyd and Mieczkowski (1990) reported greater social isolation among female than male crack users interviewed in an urban treatment center, and recent ethnographic studies of urban crack use have documented lives characterized by alienation and damaged social support networks (Carlson \& Siegal, 1991; Murphy \& Rosenbaum, 1992).

An important female relationship for many addicted women is with their mother. The significance of the adult mother-daughter relationship in the lives of both African-American and white women is becoming more apparent in current psychologic theories and recently has been explored in women with substance abuse problems (Boyd \& Guthrie, 1996; Boyd, Guthrie, Pohl, Whitmarsh, \& Henderson, 1994; Pohl \& Boyd, 1992; Wilsnack \& Wilsnack, 1991).

It's a tie between my mother and my baby, they runnin' neck and neck you know. If there was a tragedy, I'd be shot 'cause I don't know which one to go get first. If there was a fire I be tryin' to grab both of 'em. I'd probably be goin' for her [the baby] and hollerin' 'mama, mama.' You know my sister and my little brother and them, they're very important to me too. But my mom, that's my mom, that's my mother. -Belinda

Belinda's strong feelings about and identification with her mother are not unique but often are echoed by women in treatment. At the same time, many women express negative feelings about their mothers just as emphatically. Indeed, as treatment progresses, women may move between these two positions.

[My relationship with my mother is] my main pain, the stuff that hurts me inside, that's go'n' keep me usin' if I don't deal with it. I'm dealin' with what I know is go'n' send me back out there. . . . And I realize that now and that's my most angry part about it, because she helped destroy my life unconsciously, you know. And I got to get that anger out of me to where I won't blow up on her and I won't destruct myself.-Belinda

We first became aware of the power of the motherdaughter relationship for substance abusing women when interviewing women with addiction to crack. In talking to scores of women during a period of 2 to 4 
hours about all aspects of their lives, we repeatedly witnessed women becoming intensely emotional when they were asked a rather standard set of questions about attachment and conflict with their mothers. At the end of an interview, one woman responded to a routine question about how the interview had gone for her. She replied that it had not been that bad; she had expected it to be more personal. When asked what could have been more personal than the areas we had discussed, including her children, her sexual experiences, and criminal behavior, she replied, "You could have asked me more about my family, like things about my mother and me."

Attempts to understand the relationship of women with addiction to their mothers has only recently become a focus, and most has been subsumed within studies of the impact of parental substance abuse. These studies have indicated that women may be more strongly influenced than men by parental substance use (Wilsnack \& Wilsnack, 1991) and that women substance abusers are significantly more likely than men to have a mother who is a substance abuser (Boyd et al., 1993; Toray, Coughlin, Vuchinich, 1991). It is unknown what that means in terms of the pattern of abuse or treatment potential for women with addictions.

Exploring the mother-daughter relationship of women with addiction may contribute to a better understanding of women substance abusers' impaired relationships with other women and with themselves as women. Indeed, the mother-daughter relationship may be particularly significant for women with addiction who have a history of sexual abuse.

The high incidence of incest and sexual abuse in women who abuse drugs and alcohol provides a compelling reason to examine the mother-daughter dyad in relationship to women's substance abuse. Many women experience more negative feelings toward their mothers than toward the male perpetrators of their sexual abuse (Herman, 1981). Daughters often are angry at their mothers for not protecting them or for seeming to collude with the male family member who abused them. In a comparison of three groups of African-American women who abuse crack (women who have experienced incest, women who have experienced sexual abuse but not incest, and women who have not experienced sexual abuse), women who had experienced incest reported the least positive perception of their relationships with their mothers (Boyd et al., 1994).

We are only beginning to comprehend the magnitude of the impact of sexual abuse on the lives of women, including women with addictions. Exploring the relationship between sexual abuse, substance abuse, and the mother-daughter relationship will contribute to a better understanding of women substance abusers' impaired relationships with other women and with themselves as women. It may help to explain the deep animosity and lack of respect toward women (including oneself) that has led to the diagnoses in the past of "rejection of femininity" and "masculine identification" in women who use drugs and alcohol. It also may explain the paradox of addicted women expressing positive feelings toward men who are abusive toward them. In an earlier study of heroin users, Colten (1981) found that both women and men with addictions believed that women with addictions are less worthy. In addition, women heroin addicts said they felt abused by men but also thought that women need men to survive. Women who experience sexual abuse by a male family member in childhood often describe confused feelings toward the perpetrator; these women also express more clearly hostile feelings toward their mothers, who did not (could not?) protect them.

One attempt to explain this puzzling phenomenon argues that mothers in abuse situations may believe they have little economic or social power and thus no recourse to protect children from abuse. They turn their anger on themselves and deaden the pain. Daughters feel their mothers' self-anger and inability to act and feel rage at them, but they also want to help them. Daughters feel fear and admiration of male power, anguish at their own lack of resistance to that power, and their inability to protect their mothers (Sen \& Daniluk, 1995).

The interpersonal and intrapersonal relationships of women with addiction to the men, other women, and themselves as women are interwoven among themselves. Understanding these relationships and interrelationships with greater clarity allows us to provide nursing care in more sensitive and effective ways. Although there is much we do not know about these factors, the previously described level of knowledge offers several implications for treatment.

\section{Implications for Nursing Care and Substance Abuse Treatment of Women With Addictions}

Nurses encounter women with addictions in many settings and via many avenues. Unless the woman with addiction has voluntarily entered treatment, the encounters often are difficult ones and may involve some measure of confrontation, particularly if pregnancy or children are involved. Regardless of the nature of the interaction, greater awareness on the part of the nurse of the relational circumstances of the woman's life will increase the possibility of a caring encounter. Based on the theories of women's development described here and on what we know about the relationships of women with addictions, we recommend consideration of the following points when providing nursing care to this population.

First and foremost, relationships are important and need to be carefully assessed. This includes relationships 
with men and with other women. Exploring the nature of the significant relationships in her life and how they influence her drug use should be a routine part of a health assessment with woman with addictions. Questions about sexual abuse and sexual and physical violence also should be routine, and follow up with referral services, if needed, should be offered. If referral is not deemed necessary, the sensitive and complex nature of this information requires sensitive responses.

In addition to sensitivity to issues of violence in relationships, nurses may need to carefully probe women's statements regarding their feelings about men and women. If a woman with addiction says that she does not like women, does not want to be cared for by a woman, or does not want to attend an all-women's group, this should be explored in greater depth. Indeed, any strong preference for one gender or another should be carefully examined.

\section{n addition to sensitivity to issues of violence in relationships, nurses may need to carefully probe women's statements regarding their feelings about men and women.}

Except in mental health care, it is not common for health care providers to explore the relationships of adults to their parents, except to trace family histories of disease. Even in substance abuse and mental health treatment, little attention has been given to the importance of the mother-daughter relationship, except in terms of blaming the mother for the problems of the child. We are not suggesting that mothers are the key to understanding their daughter's substance abuse, but that they may be an important source of assistance in their daughter's recovery. If the daughter has a history of childhood sexual abuse, this may be even more critical. A not atypical pattern is that a women with addiction comes into treatment expressing loving or neutral feelings toward her mother, only to identify underlying rage once she has experienced sobriety for a period of time and begun to feel again. The rage needs to be handled in the course of recovery; women need to be able to blame their mothers for the hurt they have experienced as the daughters who were not mothered. They also may need to express their own sense of rage at the powerlessness of their mothers. However, the healing does not stop there. Eventually, daughters can come to understand their mother's position. Ultimately, as daughters are able to feel empathy for their mothers, they may be able to have empathy for themselves (Sen \& Daniluk, 1995). Although this is the ideal, it provides a model of the evolving mother-daughter relationship to consider when engaged in longer term therapeutic relationships with women with addictions.

Although we have focused on psychosocial assessment and intervention in the care of women with addictions, we want to emphasize that this work is not limited to nurses in the fields of mental health or addiction. Even brief encounters with nurses who convey deep understanding and compassion can have a long-term therapeutic effect in the life of a woman who has profound mistrust of other women and of herself as a woman. In addition, a compassionate encounter with one addicted women can have a positive effect on the nurse.

In this article we have stressed the importance of paying attention to the relational aspects of the lives of women with addiction. We have described the current level of knowledge about these women's relationships with men, with other women, and with themselves as women and how those relationships may interact with the substance abuse and substance abuse treatment. Finally, we have offered specific recommendations for incorporating this knowledge into the nursing care of women with addictions.

In conclusion, we want to point out what may be the obvious, returning to Belinda's words as she went through a treatment program only for women. Like Belinda, many women with addictions have lost their sense of respect and love for women, including themselves. We believe that it is essential for these women to engage in healing the relationships with other women if they are to heal the relationship with themselves (Henderson, 1992). Female nurses, as women who are sensitive to these issues and capable of providing a healing relationship, have the potential for making a profound difference in the lives of women with addictions.

I've never been one for women.

All my buddies was male and the women friends that I did have they weren't friends, really.

I knew either they wanted somethin' out of me or I wanted somethin' out of them.

Because I've never trusted women.

I always said somehow they would backstab you. My sister always did me in and ended up backstabbin' me.

My mother was never there so bow could I expect any other women to be right.

And now, I'm not go'n' say I put all my trust in 'em. But I'm go'n' give 'em a chance.

Bein' here, I learned to accept a woman as a woman. I learned that all women ain't bad.

I might not be able to live with 'em, but I can if I want to. 
I don't have to knock women just for bein' a woman. Because I'm also a woman.--Belinda

\section{REFERENCES}

Beckman, L., \& Amaro, H. (1986). Personal and social difficulties faced by women and men entering alcoholism treatment. Journal of Studies on Alcohol, 47, 135-145.

Benward, J., \& Densen-Gerber, J. (1971). Incest as a causal factor in anti-social behavior. Contemporary Drug Problems: A Law Quarterly, 1, 323-340.

Bouknight, L. (1990). The public health consequence of crack cocaine. New York State Journal of Medicine, 90, 493495.

Boyd, C. (1993). The antecedents of women's crack cocaine abuse: Family substance abuse, sexual abuse, depression and illicit drug use. Journal of Substance Abuse Treatment, 10, 433-438.

Boyd, C., Blow, F., \& Orgain, L. (1993). Gender difference among African American substance users. Journal of Psychoactive Drugs, 25, 301-305.

Boyd, C., \& Guthrie, B. (1996). Women, their significant others, and crack cocaine. The American Journal on Addictions, 5(2) 1-11.

Boyd, C., Guthrie, B., Pohl, J., Whitmarsh, J., \& Henderson, D. (1994). African-American women who smoke crack: Sexual trauma and the mother-daughter relationship. Journal of Psychoactive Drugs, 26, 243-247.

Boyd, C., \& Mieczkowski, T. (1990). Drug use, health, family and social support in 'crack' cocaine users. Addictive Behaviors: An International Journal, 15, 481-485.

Carlson, R., \& Siegal, H. (1991). The crack life: An ethnographic overview of crack use and sexual behavior among African-Americans in a Midwest metropolitan city. Journal of Psychoactive Drugs, 23, 11-20.

Chodorow, N. (1989). Feminism and psychoanalytic theory. New Haven, CT: Yale University.

Collins, P. (1990). Black feminist thought: Knowledge, consciousness, and the politics of empowerment. London: Harper Collins Academic.

Comaz-Diaz, L., \& Greene, B. (1995). Women of color: Integrating ethnic and gender identities in psychotherapy. New York: Guilford.

Colten, M. (1981). A description and comparative analysis of self-perceptions and attitudes of heroin-addicted women. In A. J. Schecter (Ed.), Drug dependence and alcobolism (Vol. 1). New York: Plenum.

Douglas, J., \& Nutter, C. (1986). Treatment changes in sex roles of addicted men and women. Journal of Studies on Alcohol, 47, 201-205.

Greene, B. (1990). What has gone before: The legacy of racism and sexism in the lives of black mothers and daughters. Women \& Therapy, 9, 207-230.

Henderson, D. (1992). Is woman born or made: Female gender identity and women's health. In J. Thompson, D. Allen, \& L. Rodrigues-Fisher (Eds.), Critique and freedom: Working papers in the politics of nursing (pp. 117-127). New York: National League for Nursing.

Henderson, D., \& Boyd, C. (1992). Masculinity, femininity and addiction. In T. Mieczkowski (Ed.), Drugs, crime and social policy (pp. 153-166). Boston: Allyn \& Bacon. Henderson, D., \& Boyd, C. (1995). Women and illicit drugs: Sexuality and crack-cocaine. Health Care for Women International, 16, 113-124.

Henderson, D., Boyd, C., \& Mieczkowski, T. (1994). Gender, relationships, and crack-cocaine: A content analysis. $R e-$ search in Nursing and Health, 7, 265-272.

Herman, J. (1981). Father-daughter incest. Cambridge, MA: Harvard University.

Higgins, S., Budney, A., \& Bickel, W. (1994). Participation of significant others in outpatient behavioral treatment predicts greater cocaine abstinence. American Journal of Drug and Alcohol Abuse, 20, 47-56.

Ladwig, G., \& Anderson, M. (1989). Substance abuse in women: Relationship between chemical dependency of women and past reports of physical and/or sexual abuse. Journal of the Addictions, 24(8), 739-754.

Lara-Cantu, M., Medina-Mora, M., \& Gutierrez, E. (1990). Relationship between masculinity and femininity in drinking in alcohol-related behavior in a general population sample. Drug and Alcohol Dependence, 26, 4554.

Lundy, C. (1987). Sex-role conflict in female alcoholics: A critical review of the literature. Alcoholism Treatment Quarterly, 4, 69-78.

Miller, B., \& Testa, M. (1993). Interrelationships between victimization experiences and women's alcohol use. Journal of Studies on Alcohol, Sept (Suppl 11), 109-117.

Miller, J. (1991). The growth of women's sense of self. In J. Jordan, A. Kaplan, \& J. Miller (Eds.), Women's growth in connection (pp. 51-66). New York: Guilford.

Murphy, S., \& Rosenbaum, M. (1992). Women who use cocaine too much: Smoking crack vs. snorting cocaine. Journal of Psychoactive Drugs, 24, 381-388.

Paone, D., \& Chavkin, W. (1992). The impact of sexual abuse: Implications for drug treatment. Journal of Women's Health, 1(2), 149-153.

Pohl, J., \& Boyd, C. (1992). Female and addiction: A concept analysis. In T. Mieczkowski (Ed.), Drugs, crime and social policy (pp. 138-152). Boston: Allyn \& Bacon.

Ratner, M. (1993). Crack pipe as pimp: An ethnographic investigation of sex-for-crack. New York: Lexington.

Root, M. (1989). Treatment failures: The role of sexual victimization in women's addictive behavior. American Journal of Orthopsychiatry, 59, 542-549.

Rosenbaum, M. (1981). When drugs come into the picture, love flies out the window: Women addicts' love relationships. The International Journal of the Addictions, 16, 1197-1206.

Schilit, R., \& Gomberg, E. (1987). Social support structures of women in treatment for alcoholism. Health and Social Work, 12(3), 187-195.

Scida, J., \& Vannicelli, M. (1979). Sex-role conflict and women's drinking. Journal of Studies on Alcohol, 40, 28-44.

Sen, C., \& Daniluk, J. (1995). Themes in the relationships of mothers and their incestuously abused daughters: A feminist analysis. Feminism and Psychology, 5, 47-60.

Sowder, B. (1981). An investigation of ways in which the drug 
treatment process affects women and men drug abusers differently. In A. J. Schecter (Ed.), Drug dependence and alcoholism (Vol. 1). New York: Plenum.

Toray, T., Coughlin, C., \& Vuchinich, S. (1991). Gender differences associated with adolescent substance abuse: Comparisons and implications for treatment. Family $R e$ lations, 4, 338-344.

Tucker, M. (1981). A descriptive and comparative analysis of the social support structure of heroin addicted women. In A. J. Schecter (Ed.), Drug dependence and alcoholism (Vol. 1). New York: Plenum.

Wilsnack, S. (1976). The impact of sex roles on women's alcohol use and abuse. In M. Greenblatt \& M. A. Schuckit (Eds.), Alcobolism problems in women and children (pp. 37-63). New York: Grune and Stratton.

Wilsnack, R., \& Wilsnack, S. (1978). Sex roles and drinking among adolescent girls. Journal of Studies on Alcohol, 39, 1855-1874.

Wilsnack, S., \& Wilsnack, R. (1991). Epidemiology of women's drinking. Journal of Substance Abuse, 3, 133-157.

Dorothy Henderson is an assistant professor in the Department of Psychosocial and Community Health at the School of Nursing of the University of Wasbington in Seattle.

Carol Boyd is an associate professor in the School of Nursing at the University of Michigan in Ann Arbor.

Address for correspondence: Dorothy Henderson, RN, PhD, Department of Psychosocial and Community Health, Box 357263, Seattle WA 98195-7263.

For information about earning continuing education credit using this and other Clinical Issues articles, call AWHONN, 800-6738499, extension 1623. 